\title{
Effect of electrode polarity on fatigue life in EDM
}

\author{
Hacı Bekir Özerkan ${ }^{1, *}$ \\ ${ }^{1}$ Gazi University Technical Sciences Vocational School, 06374 Yenimahalle/Ankara, Turkey
}

\begin{abstract}
In this study, high manganese steel specimens were machined with graphite electrode and various processing parameters by electro erosion method. It is a known fact that the craters generated by the EDM have a notch effect on the fatigue life. Therefore, $\mathrm{Rz}$ and $\mathrm{Sm}$ roughness parameters are calculated as the roughness maximum crater depth and width, respectively, and the theoretical fatigue life calculations are performed on the treated surfaces. In the processes, the tool polarization was also changed and the measured roughness values were higher in the positive polarity, so that the fatigue limit life was reduced in the calculations made with the area ${ }^{1 / 2}$ model. In EDM, when using a graphite electrode, in the case of reverse polarity machining, the surface roughness has an effect on increasing the fatigue life.
\end{abstract}

\section{Introduction}

Surface integrity of the machine elements after manufacturing is one of the most important factors affecting the fatigue life. The surface roughness is a part of surface integrity and is one of the factors that affect the fatigue life as a notch. Fatigue damage, begins in the valley-valley regions of roughness and leads to capillary cracks causing damage to the machine elements $[1,2]$. There are many different manufacturing methods in the fabrication of machine elements. In each of these manufacturing techniques, roughness values are obtained with different roughness patterns depending on the processing parameters. In the case of electro erosion, the surface pattern is completely different from other manufacturing techniques and has a crater-like appearance.

The electrical polarization of the tool-work pair in the machining by electro erosion is an important choice affecting machining performance [3]. Workbench manufacturers offer this choice to their users. In EDM, the positive polarity of the tool is called reverse polarity and the negative polarity is the direct polarity [4]. Negative charged copper tools reduces surface roughness significantly compared with other tool materials in both normal and distilled water as processing liquid [5]. Electrode polarity is an important influence to achieve better machining performance in terms of design and formability. It is known that the highest machining rate (MRR) values are obtained with negatively charged graphite electrodes, whereas the lowest roughness values are obtained with negatively charged copper tools [6]. It is known that positive polarity in dry EDM is effective because it helps

\footnotetext{
* Corresponding author: ozerkan@ gazi.edu.tr
} 
to reduce the initial discharge spark and facilitates stabilization in the process [7]. In a study graphite and copper tools have been compared in forming XW42 tool steel in EDM and emphasized that MRR with graphite tool offer lower machining rates than copper tool under the same processing conditions, and also graphite tools lower the surface roughness, and also tool wear rate (TWR) is maximum while using graphite as a tool material [8].

In addition to these types of researches, some studies have been carried out in which the effect of surface roughness on fatigue in EDM. Some researchers evaluated the surface roughness effect on fatigue life under monotonic and fatigue loading conditions. It was emphasized that random sparks caused a slight subsurface softening under the outer surface layer of the microstructure in EDM. So the fatigue strength is significantly reduced in processing with increment of surface roughness. The reduction in fatigue reaches even further levels as surface crater sizes increase with increasing current [9]. In another study [10], the effect of surface integrity of AISI D2 tool steel which coated with physical vapour deposition (PVD) of titanium nitride (TiN) on fatigue life after electrical discharge machining. Experimental results have shown that conventional EDM process reduces the fatigue life but TiN coating increases the fatigue life due to the increase of hardness and decreases the surface residual stresses. A wider study [11], offers electrochemical polishing or bead blasting as a fatigue life inducer if performed after EDM of Ti6Al4V. It's emphasized that [12] residual tensile stresses measured as $\sim 500 \mathrm{MPa}$ and $\sim 200 \mathrm{MPa}$ respectively on the machined surfaces formed by milling and EDM techniques in which austenitic stainless steels were machined with different values. Also, EDMed specimens showed 4-point bending test results, less plastic deformation observed compared to milling.

In addition, in some studies it has been stated that combining residual stresses with applied fatigue stresses, changes the average fatigue strength [13-15] and also tensile residual stress is a triggering and enhancing effect of fatigue damage and compressive residual stress is more beneficial. Residual compressive stresses are known as displacing crack damage initiation from the surface to the sub-surfaces $[16,17]$. Therefore, it can be said that tensile stresses with conventional EDM conditions have a decreasing effect on the fatigue life.

In current publications, surface integrities formed by EDM or other techniques directly affects the fatigue life. Therefore, the EDM offers a completely different pattern from the others as surface roughness design, and it is known from studies that the presence of a rapidly hardened capillary cracked layer on the surface affects the fatigue. In this study, theoretically the surface roughness is predicted by the fatigue effect model. The difference of this study from the other studies is to evaluate the surface roughness results subjected to reverse and direct polarity with the graphite tools of fatigue life. In literature, reverse polarity means positive electrode and direct (straight) polarity is also called negative electrode.

\section{Experimental and theoretical procedures}

\subsection{Experimental design and method}

The experiments were performed on Furkan die-sinking EDM 100A using kerosene dielectric with lateral flushing. High manganese steel specimens were prepared in dimensions 30mmX40mmX10mm and chemical composition of them are given in Table 1 . Before EDM operations all surfaces of specimens are ground. Good conductive graphite electrodes were selected with diameter $20 \mathrm{~mm}$ diameter. 
Table 1. Chemical composition of Hadfield steel

\begin{tabular}{|c|c|c|c|c|c|c|c|c|}
\hline & $\mathrm{C}$ & $\mathrm{Si}$ & $\mathrm{Mn}$ & $\mathrm{Cr}$ & $\mathrm{Mo}$ & $\mathrm{Ni}$ & $\mathrm{Cu}$ & $\mathrm{Fe}$ \\
\hline Hadfield Steel & 1,08 & 0,62 & 13,6 & 0,72 & 0,26 & 0,3 & 0,18 & 83,2 \\
\hline
\end{tabular}

The experimental parameters were selected as shown in Table 2. Parameters like as flushing pressure at 0,5 bar, open circuit voltage of $80 \mathrm{~V}$ and machining depth of $1 \mathrm{~mm}$ were kept constant.

Table 2. Machining parameters.

\begin{tabular}{|c|c|}
\hline Pulse on time, $\mathrm{T}_{\text {on }}(\sqcup \mathrm{s})$ & $3,6,12,24,48,99,201$ \\
\hline Pulse off time, $\mathrm{T}_{\text {off }}(\sqcup \mathrm{s})$ & $3,6,12,24$ \\
\hline Machining current, I (A) & $6,12.5,25,50$ \\
\hline
\end{tabular}

In this study, 28 reverse polarity and 28 direct polarity machining's were carried out. All experiments were repeated twice and The averages of the measurement results were taken and mean values were used in the theoretical calculations. Surface roughness measurements were performed by TR200 roughness device. $\mathrm{Rz}$ and $\mathrm{Sm}$ roughness parameters are assumed to be the notch sizes to initiate fatigue damage in "(area $)^{1 / 2}$ " fatigue model, so these values were recorded.

\section{$2.2 \sqrt{\text { area }}$ fatigue life method}

Murakami defined and expressed four factors effecting on fatigue strength: (1) surface roughness as a stress inducer, residual stresses occurred after machining, (3) work hardening or softening which occured after plastic deformation, (4) microstructure change after plastic deformation. And he also stated that, these four factors normally affect the fatigue life together, but it is difficult to theoretically evaluate the fatigue strength together with these four factors [13]. In his first studies carried out, performed tensile and compression fatigue tests using maraging steel $(\mathrm{HV}=715)$. And presents a parameter model in which the surface roughness is expressed as a shallow constant pitch and depth a periodic notch which called "area ${ }^{1 / 2}$ " [18].

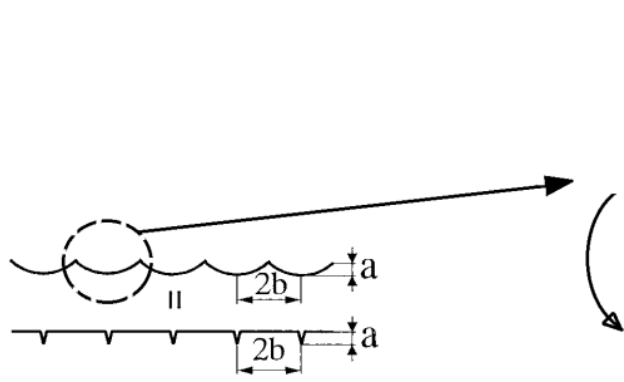

(a)

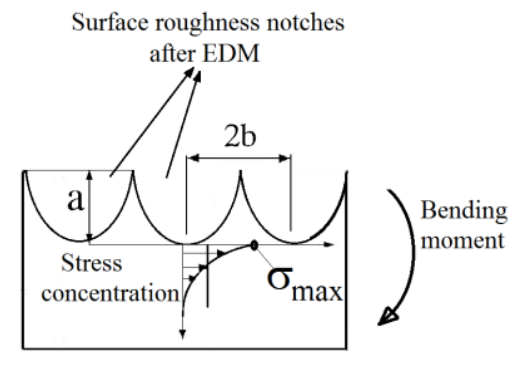

(b)

Fig. 1. a) Stress intensity zones for periodic surface roughness notches [13], b) Stress concentration distribution at valley of roughness profile in 2 dimension.

Fig. 3 shows the stress intensity zones (peak-valley of single surface roughness pattern) for periodic surface roughness pitches on machined surface. $\mathrm{Rz}$ is used instead of the average of all $\mathrm{R}_{\mathrm{z}} \equiv \mathrm{a}$ values in the measurement length which defined as maximum peakto-valley height. And also, $\mathrm{Sm} \equiv 2 \mathrm{~b}$ is the average of the distances between consecutive 
peaks on the average line along the measurement length. The term threshold stress intensity factor " $\mathrm{K}_{\mathrm{th}}$ " is defined by the following equation as a function of Vickers hardness (HV):

$$
\mathrm{K}_{\mathrm{th}}=(3,3) \cdot 10^{-3} \cdot(\mathrm{HV}+120) \cdot\left(\operatorname{area}^{-1 / 2}\right)^{1 / 3}
$$

Murakami proposed a prediction equation which takes into account the effect of mean stress should be based on the equation for $\mathrm{R}=-1$ (stress ratio), that is Eq. 2.3. For $\mathrm{R}=-1$ the equation should reduce to Eq. 2.5.

$$
\begin{gathered}
(\text { area })^{1 / 2} / 2 \mathrm{~b} \cong 2.97(\mathrm{a} / 2 \mathrm{~b})-3.51(\mathrm{a} / 2 \mathrm{~b})^{2}-9.74(\mathrm{a} / 2 \mathrm{~b})^{3} \text { for } \mathrm{a} / 2 \mathrm{~b}<0.195 \\
(\text { area })^{1 / 2}{ }_{\mathrm{R}} / 2 \mathrm{~b} \cong 0.38 \text { for } \mathrm{a} / 2 \mathrm{~b}>0.195 \\
\sigma_{f l} \cong \frac{1,43(H V+120)}{(\sqrt{\text { area }})^{1 / 6}}\left[\frac{1-R}{2}\right]^{\alpha}
\end{gathered}
$$

Using this $\sqrt{\text { area }}$ equations for $\mathrm{R}=-1$ in eq.2.4; it can be used to predict the fatigue limit of the specimens using surface roughness and of those with an average notch (Sm) and pitch $(\mathrm{Rz})$. " $\sigma_{\mathrm{fl}}$ " is the allowable stress amplitude equation for theoretical estimating and evaluation of materials with surface roughness. Here " $\alpha$ " stress sensivity factor and defined as;

$$
\begin{gathered}
\alpha=0.226+H V \times 10^{-4} \\
R=\frac{\sigma_{m}-\sigma_{w}}{\sigma_{m}+\sigma_{w}}
\end{gathered}
$$

Here " $\sigma_{\mathrm{m}}$ " is mean stress value. In this study, all equations (2.1)-(2.6) were used for predicting the fatigue life of the electrical discharged machined high manganese steel which machined under direct and reverse polarity conditions.

\section{Results and discussion}

In this study, surface roughness values such as $\mathrm{Rz}$ and $\mathrm{Sm}$ were studied for predicting of fatigue life of electrical discharge machined parts using area ${ }^{1 / 2}$ model. Fatigue life is determined as the crater area of material eroded from the work piece. The surface roughness $\mathrm{Rz}$ and $\mathrm{Sm}$ values variation due to the $\mathrm{T}_{\text {on }}$ of the machined pieces are shown in Fig. 2. Surface roughness status has worsened with the increase of pulse duration and current, but however at direct polarity case $\mathrm{Rz}$ and $\mathrm{Sm}$ values are higher than the reverse polarity condition. This real trend is contrary to reverse polarity situation [19-21]. This effect may be because of higher electrical conductivity of graphite electrodes which forms more powerful sparks to generate deeper and wider craters in contrast with the increment of $\mathrm{I}$ and $\mathrm{T}_{\mathrm{on}}$ at direct polarity. Thus this higher impact electrical forces carved and formed more deep and wide discharge craters. Consequently, by using graphite tools with direct polarity is composes rougher surfaces. This result is evident from the graphs in Fig. 2. Therefore, it can be expressed that lower surface roughness may only be achieved with low I and $\mathrm{T}_{\text {on }}$ with graphite tools at reverse polarity. By generation of deep and wide craters due to electrical conductivity and melting point of graphite tools, fatigue lives, changes due to the $\mathrm{Rz}$ and $\mathrm{Sm}$ parameters. As shown in Fig. 3, the range of determined maximum and minimum values (area) ${ }^{1 / 2}$ are explicit according to roughness change. This parameter is a 
measure of the notch dimension in the two-dimensional plane of peak-valley regions in surface roughness wave and can be assumed to be the origin of the fatigue. Because of that increasing $\mathrm{Rz}$ and $\mathrm{Sm}$ values increased (area) ${ }^{1 / 2}$ values, so this notch parameter increased with increasing current and $\mathrm{T}_{\text {on }}$ values.
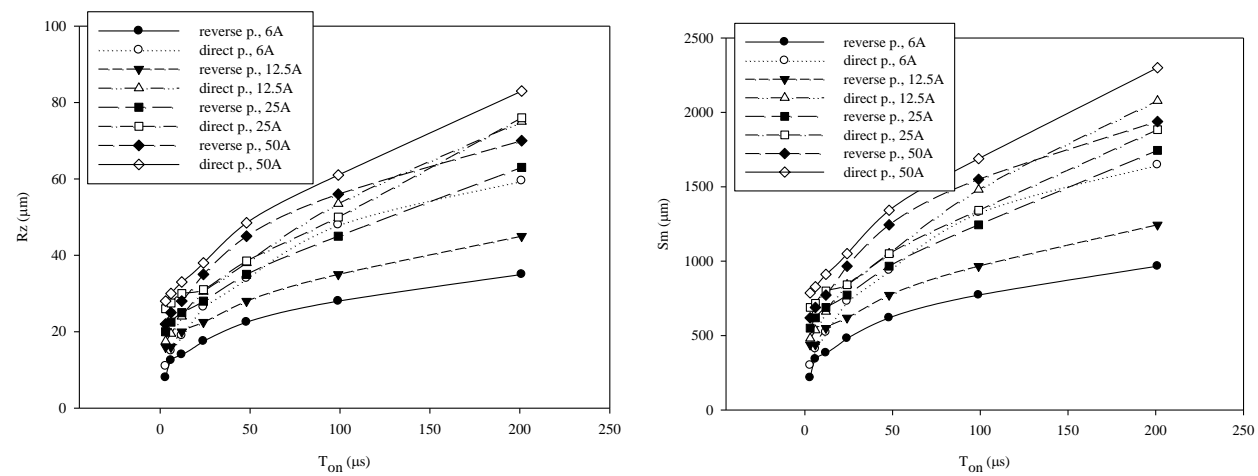

Fig. 2. $\mathrm{Rz}$ and $\mathrm{Sm}$ variation versus to $\mathrm{T}_{\mathrm{on}}$ and $\mathrm{I}$.

The critical stress intensity factor is largely dependent on the crack length and boundary conditions. In this study, the roughness of the surface peak-valley region can be regarded as a notch and initiation point of the damage. The increment of the roughness change in the distribution of the stress field in the plate surface. So as seen in Fig. $3 \mathrm{~K}_{\mathrm{th}}$ is also increasing by increment of $\mathrm{Rz}$ and $\mathrm{Sm}$. These discontinuities on the machined surfaces cause crack propagation and fatigue and explains that how they significantly reduce strength of machined parts. In other words, if there is a roughness wave in the critical dimensions on the machined surfaces, the material will break at a stress value below the yield strength (the crack will start to progress). In short, the material will break without showing yield. Therefore, this model is very useful in numerically evaluating $\mathrm{K}_{\mathrm{th}}$, stress accumulation regions. As can be seen from Fig. 3, increment of processing current and $\mathrm{T}_{\text {on }}$ values are also increased Kth values. Also, in processing with such tools in direct polarity higher surface roughness values were obtained and so higher stress intensity factors are determined.
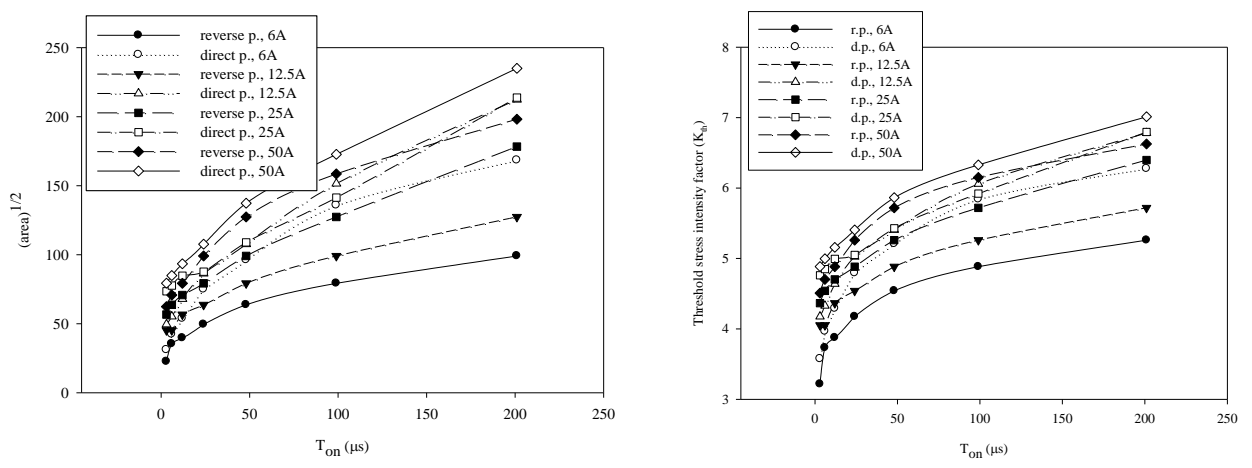

Fig. 3. $(\text { area })^{1 / 2}$ and $K_{\text {th }}$ variation versus to $T_{\text {on }}$ and $I$.

Fatigue life determination was performed by area ${ }^{1 / 2}$ to investigate the crack initiation life and theoretical endurance life. Roughness of machined surface's is commonly known as initiator and trigger of fatigue damage mechanism, so fatigue life is mostly influenced by $\mathrm{K}_{\mathrm{th}}$ which caused by surface defectiveness and irregularities [13]. And also, Fig.4 shows the 
change in the fatigue life according to surface roughness and area ${ }^{1 / 2}$ values. All curves indicate that the fatigue life is reduced by the machining current and $\mathrm{T}_{\text {on }}$.

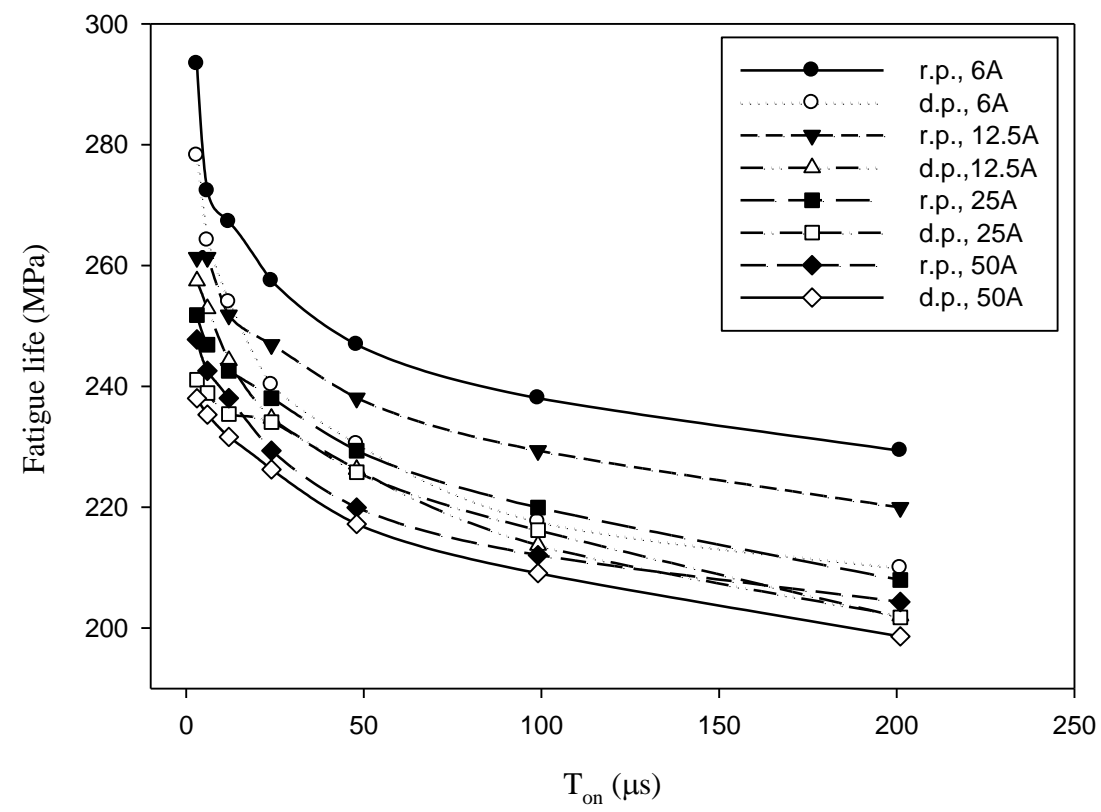

Fig. 4. Fatigue limit life variation versus to $T_{\text {on }}$ and $I$.

As emphasized earlier, these two process parameters increase the roughness and increase the stress concentrations $\left(\mathrm{K}_{\mathrm{th}}\right)$ over machined surface. Hence, it may be said that; the highest roughness peak-valley values and the discontinuity area at this point along the roughness wave structure reduce the fatigue life by forming the greatest notch effect. The highest values of fatigue life were obtained in machining's with the reversed tool and moreover the measured low roughness values in these machining are proof of this case. The maximum fatigue life was determined as $293,37 \mathrm{MPa}$ in the case of reverse tooling at $\mathrm{T}_{\mathrm{on}}=3 \Gamma \mathrm{s}$ and $\mathrm{I}=6 \mathrm{~A}$ parameters, and the minimum value was as $198,6 \mathrm{MPa}$ at $\mathrm{T}_{\text {on }}=201 \Gamma \mathrm{s}$ and $\mathrm{I}=50 \mathrm{~A}$ with direct polarized processes. The maximum $\mathrm{Rz}$ and $\mathrm{Sm}$ values were measured at the value of lowest fatigue life was determined.

\section{Conclusion}

In the study, a simple, satisfactory and cost effective theoretical prediction of fatigue strength after EDM operation with graphite tools in reverse and direct polarized tool conditions is presented. For theoretical evaluation, area ${ }^{1 / 2}$ surface roughness fatigue life model was used and the following results are obtained.

The highest $\mathrm{Rz}$ and $\mathrm{Sm}$ were obtained at highest $\mathrm{I}$ and $\mathrm{T}_{\text {on }}$ values by direct polarity and lowest ones are at lowest machining parameters by reverse polarity. Determined (area) ${ }^{1 / 2}$ values by using $\mathrm{Rz}$ and $\mathrm{Sm}$ values were the lowest at $\mathrm{T}_{\text {on }}=3\ulcorner\mathrm{~s}$ and $\mathrm{I}=6 \mathrm{~A}$ with reverse polarity and highest at $\mathrm{T}=201 \Gamma \mathrm{s}$ and $\mathrm{I}=50 \mathrm{~A}$ with direct polarized processes. This is in agreement with the greatness and smallness of roughness pattern. Increasing the $T_{\text {on }}$ and $I$ and changing electrode polarity from reverse to direct increased the $\mathrm{Rz}$ and $\mathrm{Sm}$ parameters by within the range of $7,21 \sim 41,6 \%$ and $7,25 \sim 41,84 \%$ respectively. Current has much 
influence on roughness compared to $\mathrm{T}_{\mathrm{on}}$. For all direct electrode processes $\mathrm{Rz}$ and $\mathrm{Sm}$ values were measured high.

Theoretical fatigue life extended with decrease of $\mathrm{I}$ and $\mathrm{T}_{\mathrm{on}}$. By changing polarity of electrode to reverse case instead of direct, the fatigue life increased by $1,2 \sim 8,5 \%$ of the total increment and also Kth has reduced by $2,4 \sim 16,4 \%$. Polarity variation has considerable influence on fatigue life. Shortly, a rougher surface will shorten the crack initiation life and also the fatigue life because the fatigue crack initiation is more easily on a rough surface.

So roughness sizes are the most efficient estimator of fatigue life after different types of machining. It can be highlighted from this work that the crack initiation and fatigue life are predominantly affected by I and Ton in EDM.

\section{References}

1. S.R. Schmid, B.J. Hamrock, B.O. Jacobson, Fundamentals of machine elements: SI version, (2014)

2. J. P. Davim, Surface integrity in machining: Springer, (2010)

3. H.A.-G. El-Hofy, Advanced machining processes: non-traditional and hybrid machining processes, (2005)

4. C.C. Haron, B.M. Deros, A. Ginting, M. Fauziah, J. of Mat. Pro. Tech. 116, 84-87 (2001).

5. S.T. Jilani, P.C. Pandey, Int. J. Mach. Tool. Des. Res. 24 (1), 31-43 (1984)

6. F.L. Amorim, W.L. Weingaertner, J. of the Bra. Soc. of Mec. Sci. and Eng., 29, 366371 (2007)

7. L.Q. Li, W.S. Zhao, Z.L. Wang, B.Q. Kou, L.Y. Li, $31^{\text {st }}$ IEEE Int. Conf. on Plas. Sci. (2004)

8. C.C. Haron, J.A. Ghani, Y. Burhanuddin, Y. Seong, C. Swee, J. of mat. Pro. Tech. 201, 570-573 (2008)

9. M. Ramulu, G. Paul, J. Patel, Composite structures, 54, 79-86 (2001)

10. Y. Guu, H. Hocheng, Materials Science and Engineering: A, 318 (1-2), 155-162 (2001)

11. T.M. Mower, International Journal of Fatigue, 64, 84-96. (2014)

12. M. Lundberg, J. Saarimäki, J.J. Moverare, M. Calmunger, Mat.Charac., 124, 215-222 (2017).

13. Y. Murakami, Metal fatigue: effects of small defects and nonmetallic inclusions, Elsevier, (2002)

14. K. Shiozawa, Y. Morii, S. Nishino, L. Lu, Int. J. of Fatigue, 28, 1521-1532 (2006).

15. M. Kobayashi, Y. Murakami, T. Makino, T. Toriyama, Y. Kurihara, R. Ebara, Impact of Imp. Mat. Qua. on Propert., Prod. Perf., and Dsgn., MD, 28, 171-183 (1991).

16. M.A. Xavior, N. Ranganathan, P. Ashwath, Mat. Today: Proce., 5, 12666-12672 (2018).

17. Z. Chen, J. Moverare, R.L. Peng, S. Johansson, Procedia CIRP, 45, 307-310 (2016)

18. Y. Murakami, K. Tsutsumi, M. Fujishima, Trans. Jpn. Soc. Mech. Eng. Ser. A, 62 (597), 1124-1131(1996),

19. F. Han, Y. Yamada, T. Kawakami, M. Kunieda, Prec. Eng., 30, 123-131 (2006).

20. Y.C. Lin, B.H. Yan, F.Y. Huang, Int. J. of Adv. Man. Tech., 18, 673-682, (2001a),,

21. Y.C. Lin, B.H. Yan, F.Y. Huang, J. of Mat. Pro. Tech. 115, 359-366 (2001b). 